\title{
El burlador de Sevilla, don Juan antes del mito
}

Miguel Ángel Zamorano Heras

\section{Resumen}

Es posible suponer que muchos lectores tengan una idea del donjuanismo derivada de otras versiones y orquestada en la sensibilidad de otras preocupaciones y épocas. Sorprende constatar que aquello que atrajo posteriormente el interés de escritores y públicos de diferentes tradiciones literarias no coincida con lo que su primer autor quiso tratar, es decir, que la erotomanía compulsiva de un personaje que expresa paradójicamente la inconstancia y la imposibilidad de amar, asunto tan atractivo para la mentalidad contemporánea, no fuera en la pieza original ni el tema vertebral ni un fin en sí mismo, sino un medio para teatralizar otras preocupaciones como la impunidad del poderoso, el buen gobierno de la república, la corrupción de los jóvenes nobles y la salvación de las almas. En este artículo comentaré algunos aspectos de este clásico de la dramaturgia, con el propósito de despertar en el lector no especializado el interés por sus temas conexos y el complejo intertexto, tanto sincrónico como diacrónico, en el que inevitablemente se inserta su interpretación: el teatro español del Siglo de Oro y el contexto sociopolitico de la época.

Palabras clave: Don Juan; El burlador de Sevilla; Tirso de Molina; Teatro del Siglo de Oro. 


\section{Introducción}

Resulta curioso que en El burlador de Sevilla ${ }^{1}$, su personaje principal, don Juan, esté obsesionado con su propia fama, circunstancia que para otros personajes de la comedia, dicha gloria que persigue a toda costa "El mayor burlador de España" no es sino infamia. Esta divergencia de apreciaciones divide la obra en dos perspectivas antitéticas, la de quienes consideran, como el burlador, que la fama es un valor absoluto, digno de conquistarse a cualquier precio, y la de quienes opinan que la gloria sólo honra cuando los actos son heroicos, es decir, compatibles com la moral del grupo social hegemónico. En este sentido, don Juan es un transgresor integral y sin fisuras, contrario a esa forma de heroísmo. Actitud que, sin embargo, no lo convierte en un revolucionario en el sentido moderno, pues su rechazo a las normas y la ruptura con ellas no obedece a un ideal que las sustituya sino a una autoexigencia privada y egocéntrica, de naturaleza enteramente narcisista. Su irresponsabilidad social y la negligencia de sus deberes se explican como consecuencia de un individualismo exacerbado que se concentra en satisfacer sus apetitos, a costa de despreciar los valores que cohesionan y dan sentido al cuerpo social del que forma parte. Como personaje dramático, va a contrapelo de lo que representa y es. Desde el punto de vista social, un transgresor sin idealismo, sin ninguna visión política y con nula conciencia de estado o de la colectividad. Una figura solitaria que hace la guerra por su cuenta con la obediencia admonitoria de su criado Catalinón. Desacata las normas y la autoridad pero sabiendo que ese mismo poder le va a proteger: "Si es mi padre / el dueño de la justicia / y es la privanza del rey / ¿qué temes? (VV. 1994-1997)". Don Juan nace en una familia poderosa e influyente, pero él trata de negociar algo tan valioso para un noble como su sentido de pertenencia, pues cuando Isabella le pregunta “Quién eres, hombre?" él responde: "¿Quién soy? Un hombre sin nombre" (VV.14-15). Este acto voluntario de borrado de identidad define al personaje en los

1 Todas las citas en este artículo sobre El burlador de Sevilla corresponden a la edición de Cátedra, de Alfredo Rodríguez López-Vázquez (ver bibliografía). primeros versos de la comedia. Don Juan, en más de un sentido, es un personaje ambiguo, capaz de suscitar sentimientos e impresiones muy diferentes en sus lectores. Américo Castro escribió: “Nos sentimos solicitados y repelidos por tan compleja figura, mezcla de bienes y males, portadora de un tremendo 
dinamismo, de una voluntad audaz, cuya finalidad excede a la puramente negativa de desencadenar los rayos del infierno". (Castro, XXVII, en Tirso de Molina, 1932). Lo cierto es que la fama que obsesivamente procura don Juan en la ficción saltó a la historia y terminó por convertirse en uno de los personajes más célebres de la literatura dramática de todos los tiempos. Dicha circunstancia produjo en su caso efectos contradictorios, pues su fecunda estirpe propició tantas variaciones que el conocimiento del don Juan original fue relegado a un nebuloso fondo cubierto por numerosas capas literarias y ensayísticas. Es plausible que muchos lectores posean una idea del donjuanismo derivada de otras versiones y orquestada en la sensibilidad de otras preocupaciones y épocas. Lo asombroso es constatar que aquello que atrajo posteriormente el interés de escritores y públicos de diferentes tradiciones literarias no coincide con lo que su primer autor quiso abordar, esto es, que la erotomanía compulsiva de un personaje que expresa paradójicamente la inconstancia y la imposibilidad de amar, asunto tan atractivo para la mentalidad contemporánea, no era, en la obra original, ni el tema vertebral ni un fin en sí mismo, sino un medio para teatralizar otras preocupaciones, como la impunidad del poderoso, el buen gobierno de la república, la corrupción de la juventud nobiliaria y la salvación de almas.

\section{Fortuna crítica e intertextualidad}

En las Actas del primer Coloquio Internacional de Hispanistas, celebrado en Oxford en 1964, Heinrich Bihler expresó la dificultad de presentar "nuevos hallazgos sobre un tema tan conocido y discutido como El Burlador de Sevilla y Convidado de piedra, siendo tan inmensa y en parte tan difícilmente accesible su bibliografía sobre este tema". De modo que consideraba apropiado justificarse: "es preciso contar con el hecho de que algunas de las siguientes observaciones hayan sido ya expuestas en estudios que yo desconozco" (1964:213). El hispanista francés Marc Vitse (1969) comenzaba su ensayo Don Juan o temor o temeridad, citando las palabras de Bihler, y siguiendo esta tradición, medio siglo después, comienzo este artículo, recordando que en este tiempo el número de contribuciones sobre esta obra se ha incrementando sin disminución de su interés. Laura Dolfi (2000) enumera una 
2 Mencionaba a Ignacio Arellano, Aurora Egido, Maurice Molho, Francisco Rico, Alfredo Rodríguez, Luis Vázquez y Francisco Vázquez Villanueva, sin olvidar las anteriores investigaciones de Américo Castro, Emilio Cotarelo, Benedetto Croce, Menéndez Pidal, Blanca de los Ríos, Joaquín Casalduero, D. W. Cruickshank, Pierre Guenoun, Lida de Malkiel, Alexander Parker, Said Armesto, Karl Vossler, Gerald Wade y Bruce Wardropper, entre otros. lista de excelentes críticos que publicaron en este último medio siglo estudios sobre El burlador de Sevilla ${ }^{2}$. Más recientemente Andreas Flurschütz (2010) intentaba dar cuenta numérica de los trabajos teatrales, literarios, audiovisuales y teóricos hasta mitad del siglo $\mathrm{XX}$, originados a partir de la obra teatral de Tirso de Molina, donde la leyenda del falso seductor y tramposo mujeriego cristaliza en su primera forma literaria:

Desde el siglo XVII el Don Juan influye en toda la cultura europea (Hammer 1994:15), así que el tema donjuanesco probablemente es el tema teatral y literario más difundido y tratado del mundo (CI: 459), o en palabras de James A. Parr, hablando de Don Quijote y Don Juan: "the two most important figures bequeathed to the wider world by Spanish literature" (Parr 2004:9). Hasta mediados del siglo XX se han registrado 4460 publicaciones que tratan este tema (Singer 1965), de los cuales 2200 son dramas (SB: 29-38), y cuando se habla de un Don Juan hoy día su presencia en el imaginario popular continúa siendo muy intensa (Baruch 2005:16). (Flurschütz, 2010).

El burlador de Sevilla responde a las características de un texto fundacional de la literatura occidental, tanto por el acierto al captar en un carácter literario rasgos y pulsiones de la mente y la biología humana cuanto por la influencia que ejerce posteriormente en diversos géneros y literaturas nacionales. Tal vez no sea exagerado afirmar que su inevitable figura origina uno de los intertextos más colosales y fecundos de la literatura moderna. Si pensamos en su carismático personaje, no se encontrará en la literatura española, a excepción de don Quijote, uno que se le equipare en fama. Y si lo consideramos estrictamente desde el campo teatral, don Juan es indiscutiblemente el personaje que más lo transciende, pues además de en numerosas obras teatrales aparece en novelas, óperas, películas y hasta en manuales de psiquiatría. Nos hallamos ante uno de esos raros casos de personaje literario para el cual ni las fronteras de géneros, ni las de lenguas, etnias, edades o sexo, limitan su difusión en múltiples versiones.

En un estudio sobre el mito el profesor García Gual trataba de definirlo como "algo que se dice de muchas maneras" (1989:89). Tan lacónica sentencia explica la relación entre lo uno y lo múltiple, necesarias para entender la también infinidad de singularidades y mutaciones humanas. Conocida es la tesis de Ian Watt (1999) al considerar a Fausto, don Quijote y don 
Juan los tres grandes mitos que perviven del Renacimiento y que condensan ya en su primera forma literaria los rasgos del individualismo contemporáneo. Si alcanzan fama de mito se debe a su capacidad de evocar perfiles y matices renovados, enriquecidos con el paso de los siglos a través de diversas lenguas y culturas. Dicho estatuto de mito puede explicarse, según Joseph Campbell, por contener "una visión eterna", semejante a la desprendida por un sueño que emerge de la profundidad de la mente colectiva:

Los mitos del hombre han sido la inspiración viva de todo lo que ha podido surgir de las actividades del cuerpo y de la mente humanos. No sería exagerado decir que el mito es la entrada secreta por la cual las inagotables energías del cosmos se vierten en las manifestaciones culturales humanas. Las religiones, las filosofías, las artes, las formas sociales del hombre primitivo e histórico, los primeros descubrimientos científicos y tecnológicos, las propias visiones que atormentan el sueño, emanan del fundamental anillo mágico del mito. ([1949] 2013:11)

El hecho de que una obra literaria alcance tamaña fortuna y se instale en un canon europeo, en uno teatral o en posiciones relevantes de diversos repertorios de literaturas nacionales puede resultar para el joven investigador un factor intimidatorio, debido al ingente volumen de trabajos acumulados. En este artículo comentaré algunos aspectos de este clásico de la dramaturgia, con el fin de despertar en un lector no especializado el interés por sus temas conexos y el complejo intertexto, tanto sincrónico cuanto diacrónico, en que inevitablemente se inserta su interpretación: la comedia barroca del Siglo de Oro y el contexto socio-político de la época.

\section{La obra}

Pocas cosas se saben con seguridad sobre la fecha de su composición y autoría, sólo que existen dos versiones: Tan largo me lo fiáis y El burlador de Sevilla y convidado de piedra. Blanca de los Ríos defendía que El burlador de Sevilla retomaba una versión de 1616, titulada Tan largo me lo fiáis. Esa opinión no era compartida por las ediciones de Cotarelo y de Américo Castro, quienes interpretaban, apoyados en el cotejo, que entre ambas obras Tan largo era una refundición valiosa aunque tardía de El burlador. Ruano de la Haza (1995) terciaba en esta 
polémica interpretando las dos posiciones de los editores que actualmente defienden una y otra tesis, Alfredo Rodríguez López-Vázquez, por un lado, que "cree que Tan largo es la versión original de la comedia de don Juan" y Xavier Fernández que defiende la prioridad de El burlador, concluyendo que "hasta que no se descubra evidencia documental, la paternidad de estos dos textos teatrales no tendrá solución satisfactoria para todos y de que celebremos el hecho de que en vez de una tenemos la inmensa suerte de poseer dos versiones de la inmortal comedia de don Juan" (Ruano de la Haza, 1995:296). Los problemas de autoría, también debatidos hasta hoy, salvo excepciones que defienden la autoría de Andrés Claramonte, sosteniendo la hipótesis de que este sería autor de la versión inicial, se inclinan por atribuir indiscutidamente la obra a Tirso de Molina. El debate sobre sus fuentes históricas y extraliterarias gira sobre el interrogante de si hubo un prototipo real, en la historia de la España anterior a la composición de la obra, que sirvió de modelo para la elaboración literaria de don Juan. Las indagaciones se remontan hasta la Crónica de Zurita y el reinado de Don Pedro I, entre 1350 y 1355, en donde, según López-Vázquez (1996-33), aparecen citados personajes históricos que serán retomados con los mismos nombres en $\mathrm{El}$ burlador, como Gonzalo de Ulloa, Pedro Tenorio y Juan Tenorio. Con independencia de los cotejos que puedan establecerse entre la Crónica de Zurita y el texto de Tirso, lo sustancial revela que la elaboración de esos materiales atribuibles a diversas fuentes, como crónicas, leyendas medievales y relatos folclóricos, el autor los adapta para tratar cuestiones de actualidad. Parafraseando los argumentos de López-Vázquez en su edición, los referentes pueden tomarse de la historia, ahora bien, la transposición dramatúrgica de esos materiales, que tendrían a la ciudad de Sevilla como epicentro de un modo de vida corrupto y disoluto, obedece a las preocupaciones sentidas por el dramaturgo y nos hablan de un presente problemático y en tensión.

\section{División de la comedia}

La formalidad preceptiva de las tres jornadas en la comedia barroca encubre en este caso una división de la acción en cinco episodios, secuenciados, a su vez, en dos partes. Los cuatro primeros episodios corresponden a cuatro 
aventuras amorosas, con el saldo de cuatro mujeres burladas; el quinto desarrolla el castigo al burlador en la forma irónica del burlador burlado, cerrando de este modo el principal asunto problematizado: el de la transgresión de las normas y el del castigo al transgresor. Consecuencia de una frenética y dinámica acción dramática, los cinco episodios despliegan una muy precisa cartografía: del palacio del rey de Nápoles, donde transcurre la burla de la duquesa Isabella, pasamos a una playa de Tarragona. En esta se desarrolla el segundo episodio con la burla de Tisbea, la pescadora que intenta la suerte y pierde. De aquí don Juan y su criado Catalinón se trasladan a Sevilla, para acometer la tercera de la burlas, fallida esta vez con el imprevisto suceso de la llegada del Comendador y el fatal incidente que le da muerte. De la ciudad de Sevilla, don Juan parte desterrado a Lebrija, aunque se desvía en el camino atraído por una boda de labriegos en Dos Hermanas y allí acomete el último y más "brillante", desde un punto de vista intelectual, de sus engaños. En la huida de Dos Hermanas evita el destino prefijado de Lebrija y decide nuevamente regresar a Sevilla, donde encontrará, en el trayecto que lo conduce a su posada, el sepulcro del Comendador Don Gonzalo. Este encuentro nos permitirá suponer, mediante una hermosa y calculada elipsis, que entre el episodio de Dos Hermanas y el anterior asesinato del Comendador ha transcurrido el tiempo necesario para darle sepultura y labrarle un monumento de piedra con una leyenda que dirá: "Aquí aguarda del Señor / el más leal caballero / la venganza de un traidor" (VV.23032305), ante la cual, don Juan se burlará del epitafio y después realizará lo que él debe suponer un desafío imposible de cumplir por un muerto: "Aquesta noche a cenar / os aguardo en mi posada; / allí el desafío haremos / si la venganza os agrada" (VV. 2311-2314).

\section{Los espacios dramáticos}

La relación de los espacios, el modo como se evocan y articulan creando una dinámica plasticidad, merecen un estudio aparte que resulta imposible abordar en esta breve presentación, pero mencionaré dos recursos responsables por la producción imaginaria de lugares: el relato ticoscópico de Tisbea en la playa (VV.499-517) y la escena itinerante del 
${ }^{3}$ Como en estos versos de Clarín en La vida es sueño: "Qué es lo que escucho, cielos! / Cadenita hay que suena / mátenme si no es galeote en pena" (VV.73, 75-76) comienzo de la segunda jornada (VV. 1046-1297). Técnica dramática en la cual Tirso se revela como un maestro.

El relato ticoscópico o efecto de ticoscopia actualiza en el presente enunciativo eventos que acontecen fuera de escena y que por su magnitud o complejidad resultan imposibles de materializar en el tablado. Este recurso se emplea a través del personaje y se vincula a su percepción sensorial, la vista, aunque en ocasiones también el oído ${ }^{3}$. Los versos que ilustran este efecto coinciden con el monólogo de Tisbea después de autopresentarse. La pescadora percibe, a orillas del poblado en que vive, un hombre que lucha por salvar a otro de ahogarse: "Un hombre al otro aguarda / que dice que se ahoga / gallarda cortesía / en los hombros le toma" (VV. 500-503). Ese hombre que salva a otro arriesgando su vida es don Juan. Tisbea, testigo ocular de la acción. El salvado, su criado Catalinón, y este gesto el único que atribuye a don Juan en toda la obra un rasgo de generosidad y altruismo. Tisbea lo califica de "Gallarda cortesía", apreciando una acción valerosa. La pescadora que ha inclinado su simpatía, la acrecentará cuando conozca su origen: "Es hijo aqueste señor / del Camarero Mayor / del rey... /" (VV. 571-573), le dirá el indiscreto Catalinón, y cuando lo acoja en sus brazos intentando reanimarlo dará la primera descripción física de su figura: "Mancebo excelente / gallardo, noble y galán / volved en vos, caballero" (VV. 580-582). Posteriormente, su impresión destacará la segunda y última apreciación física, unida ahora a otro aspecto: "Parecéis caballo griego / que el mar a mis pies desagua, / pues venís formado de agua / y estáis preñado de fuego" (VV. 614-617). El autor, con estos dos versos anticipa el desenlace de este episodio en una bella prolepsis cargada de ironía trágica. Tisbea, al unir en don Juan el fuego con la pasión amorosa, recurre al consabido cliché ignorando que la expresión "estar preñado de fuego" incluye un signo tan literal cuanto profético y que el dudoso galán cumplirá cuando incendie la cabaña de la pescadora después de haberla gozado, consiguiendo arrancarle esos versos que tan bien la describen: "yo soy la que hacía siempre / de los hombres burla tanta, / que siempre las que hacen burla / vienen a quedar burladas" (VV. (1014-1017). El efecto de ticoscopia, mediante la descripción por un personaje testigo de un evento complejo de representar, ha logrado crear en la lectura, que presupone una pre-escenificación de 
la representación en el tablado de los corrales, las condiciones imaginarias de una playa, una aldea de pescadores, una cabaña próxima y el movimiento de aproximación de dos náufragos exhaustos hacia la orilla.

Se llama escena o espacio itinerante a la aplicación de una técnica, un recurso dramático mediante el cual el autor origina diversos lugares en una acción aparentemente continua, sin cortes apreciables y en donde el escenario nunca queda vacío. Los personajes no llegan a salir de escena pero sí producen la sensación de movimiento porque se desplazan por esos espacios dramáticos (Rubiera, 2005:108). La sensación de dinamismo y movilidad espacial es evidente aunque no siempre se conocen las características del espacio por el que se mueven los personajes que, en muchas ocasiones, ha de ser deducido de algún detalle del diálogo, decorado verbal, o supuesto al poner en relación partes enteras de la obra. Esto es, el lector debe cooperar, co-creativamente, si quiere restablecer ese ideal de totalidad comprensiva al que en teoría aspira. Rubiera menciona: "Este recurso es el que ya Rennert, utilizando términos de Archer para caracterizar el teatro isabelino, llamó "vagueness of localization", que consideraba un hecho fundamental del drama inglés y de la comedia española de la época" (2005:109). En un estudio reciente que analiza los 77 primeros versos de La vida es sueño (Zamorano, 2014) se ponen en relación la producción de estos espacios itinerantes con los "performativos ontológicos" o palabras que, al enunciarse, "hacen el mundo ficcional" a medida que surgen y se autentifican por un personaje confiable.

El inicio de la segunda jornada de El Burlador de Sevilla genera un flujo de acción continua a través de una alternancia entre espacio dramático estático y dinámico, y en el que se suceden cuatro escenas: La primera del rey, con Tenorio el viejo y el Duque Octavio; la segunda, de transición en la que el duque, con su criado Ripio, encuentra a Don Juan y Catalinón; la tercera, cuya presencia cercana, "a la vista", del marqués de la Mota, aconseja al Duque a evitarlo, saliendo de escena; y la cuarta, en la que don Juan y Catalinón encuentran al marqués y su criado y resuelven sus asuntos hasta que estos se despiden. Este es el momento en que don Juan recibe a través de una ventana enrejada "Habla por una reja una mujer" la misión de entregar una carta al marqués de la Mota, 
ocasión que aprovechará para urdir su nueva burla. Desde el inicio hasta aquí transcurren 232 versos. Desde el 1050 hasta el 1287 la acción ha progresado ágilmente, mudando de tópico y de asunto, con la participación de ocho personajes. El escenario nunca se ha quedado vacío y, si no se observan sutiles referencias verbales, el lector pasa por alto la transición de la estancia de palacio donde el rey de Castilla despacha sus asuntos de política, en la primera escena, al exterior de una calle sevillana donde una mujer tapada entrega una carta a un desconocido, en la quinta escena. Todo hace pensar que una mujer así sólo puede estar desesperada por asumir ese riesgo, pero eso es otra cuestión. Lo cierto es que el lector repentinamente tiene que entender, y no siempre ocurre, como se comprueba en los talleres de lectura, que la acción ha pasado del palacio del rey a una de las estrechas calles de la ciudad de Sevilla y que ese flujo de espacios se ha ido diseminando, como una figura de papiroflexia que comienza a desplegarse, mientras los personajes dialogaban, sin mención explícita didascálica, encadenando una escena a otra, sin que el tablado quedara vacío y originando, consecuentemente, esos espacios dramáticos en un tiempo estilizado.

\section{La concepción del tiempo}

Si percibir el modo como el espacio y su construcción se elaboran resulta fundamental para apreciar los diversos detalles de las acciones dramáticas, el tiempo dramático posee igualmente un valor que se integra en el diseño de la comedia proyectando diversas significaciones. La obra ya comienza con dos versos apremiantes, las palabras de Isabella, recién burlada, creyendo que su amante furtivo es el duque Octavio: "Duque Octavio, por aquí / podrás salir más seguro" (VV 1-2). El éxito de la burla de don Juan a Tisbea lo fía a la velocidad de las yeguas que robará para huir del poblado: “Tú las dos yeguas apresta, / que de sus pies voladores / sólo nuestro engaño fío" (VV. 880-890). Para culminar el engaño de doña Ana se dará una hora, tiempo de que dispondrá antes de que llegue Mota. Referencia al tiempo de una noche también se encuentra en la burla a Aminta: "Bien lo supe negociar / gozarla esta noche espero / la noche camina..." (VV. 1945-47). La urgencia y la eficacia en el empleo del tiempo son distintivos 
de este personaje y un elemento constante y reiterativo de esta comedia. Constituye el rasgo psicológico que presiona a don Juan tanto en la ejecución de sus planes cuanto en la organización global de su existencia, que es la propia de un personaje monomaníaco, absorbido por la única idea que aglutina sus actividades. Para él, como para todo delincuente profesional, el tiempo empleado en la ejecución de sus actos transgresores se reviste de una cualidad diferente al tiempo ordinario, tanto por la intensidad como por la concentración con que se vive. Supone una experiencia que transciende el sentimiento del flujo cotidiano y lo transporta a un estado alterado de conciencia y de esplendor vital. Ruiz Ramón escribió: "La vida de don Juan, teatralmente, transcurre como un relámpago entre la cama y el sepulcro, entre el amor y la muerte, entre el goce y el castigo" (1978:73). Y posteriormente: "Don Juan no puede demorarse, pues quedarse es renunciar a ser quien es: quien goza y parte para gozar de nuevo" (1978:73). Sus acciones no permiten malgastar tiempo. Los remansos en los que se contempla la existencia literaria de personajes desde una perspectiva relajada son desconocidos para esta figura de la velocidad, que parece cargar sobre sus hombros el pesado fardo de su propia compulsión vital, empujándolo siempre a cumplir con su sino. Ahora bien, ¿cuál es su sino, el de gozar a la mujer o el de demostrarse a sí mismo y al resto de España su fabulosa habilidad para el engaño? ¿No es en el fondo, como se ha insinuado ya, el deseo de fama lo que mueve a don Juan? "Ha de ser burla de fama" (V. 1468), dice don Juan a Catalinón, ante la burla a doña Ana. La misma fama que repudia el padre, Tenorio el viejo, a don Juan: "verte más cuerdo quería / más bueno y con mejor fama" (VV. 1416-17). O la que denuncia Octavio al rey: "por la lengua de la fama / sabe, que Don Juan Tenorio, / con española arrogancia, / en Nápoles, una noche, / para mí noche tan mala, / con mi nombre profanó / el sagrado de una dama" (VV. 2600-6).

Hay, con relación al tiempo, otro contraste que hemos de mencionar aunque sea de pasada. Se trata del tiempo profano, que percibe el personaje y marca la acción de la comedia con su ritmo frenético, el empleado en engaños, riñas, fugas, relaciones sexuales y la conquista de fama, con el otro, el que se posterga, con la frase más reiterada de la comedia: "tan largo me lo fiáis". Parafraseándola podría equivaler al 
momento del arrepentimiento que aún puede ser postergado, y que se relaciona con el lado espiritual desatendido por el burlador, el tiempo eterno, que promete la salvación del alma, y que al final se le niega a don Juan como castigo divino por su temeridad, inconsciencia y cinismo calculador. Sobre este asunto, Casalduero escribió: “Tanto el contraste como la repetición son recursos técnicos constantes de la comedia, que en El burlador tienen un cometido espiritual especial: la confrontación de lo temporal con lo eterno" (1967:127). Para el crítico esta confrontación constituía el conflicto y el principal sentido de la obra: "el tenso dramatismo de la vida cristiana; el engaño del hombre, que consiste en entregarse ciego al tiempo relegando la eternidad". (1967:128)

\section{La burla, motivo central de la acción}

Como se ha mencionado, cada burla origina una huida, un asentamiento en un nuevo lugar y la oportunidad de otra burla. Si burlar y huir configuran una relación dialéctica, por sí sola la burla constituye la base para la acción de la comedia y el núcleo de su densidad semántica. Desde esa acción raíz se puede ascender, como si trepáramos por un árbol, y conectar todas las acciones engarzadas en el plano sintagmático y explicarlas: desde el conjunto entendemos mejor cada una de las unidades segmentadas y una vez unidas el conjunto vuelve a revelar nuevos detalles. Típico caso de motivo que estructura acciones, pues de él nacen el conjunto de eventos que componen cada uno de los cinco episodios. En todos encontramos burlas aunque el agente que burla no coincide en todos los episodios. Sólo en los cuatro primeros don Juan burla, en el quinto sufre la burla (Dolfi, 2000), por tanto, parece más adecuado una división en cinco burlas, la última de la cuales cambia al agente, ya que convierte al burlador en burlado y, acto seguido, se procede a su castigo ejemplarizante.

La burla ocasiona una polisémica diversidad de crímenes: 1) el engaño sexual, mediante la promesa del matrimonio, despoja a la joven casadera de su "honra" y la inutiliza para el matrimonio reglado, 2) rompe las relaciones, si bien es cierto que no siempre armónicas ni del todo honestas, de las mujeres burladas con su entorno y destruye los vínculos con sus pretendientes y familias, 3) al estar sujeta al fracaso y sus 
eventuales consecuencias pueden derivar en una escalada de crímenes, como el asesinato del Comendador don Gonzalo cuando acude en ayuda de su hija doña Ana, 4) por último, al constituirse en modo de vida de don Juan, transgrede principios de obligado cumplimiento para un caballero, como el respeto a la palabra dada y a las promesas de matrimonio, o el no menos importante deber de obediencia al padre y por extensión al principio de autoridad que representa en el orden social.

Don Juan burla a la mujer noble y a la plebeya. A la noble mediante suplantaciones de identidad, a la plebeya con falsas promesas de matrimonio. Su burla es, como se ha señalado, democrática. Los efectos no cambian, resultando los mismos para todos los grupos sociales: la deshonra, la vergüenza, el agravio, la humillación, el sentimiento de traición, etc. Con ello también las consecuencias llegan a los padres o prometidos. El rey de Nápoles también es burlado en el sagrado de su casa, no sólo por don Juan, también por la duquesa y el embajador de España, que protegerá al "calavera" de su sobrino a costa de desobedecer al rey. Burlados quedan el duque Octavio y el marqués de la Mota en la lealtad de su amistad. Se hará notar con esto la idea de la doble burla, pues siempre que se deshonra una mujer las consecuencias se amplían al universo masculino. Especial es el caso de doña Ana y el Marqués, ya que con esta maniobra don Juan burla a un mismo tiempo la fidelidad del amigo y el honor de su prometida. Pero la burla no se limita al mundo de los vivos y entrará en juego la burla macabra ante el túmulo de Don Gonzalo y el sarcasmo tras la lectura del epitafio, que conectará el mundo profano con el sagrado. La temeridad de Don Juan, como indicó Vitse (1969), no debe confundirse con la valentía, sino más bien con una especie de falta de juicio y torpeza en la prevención que será la propia hamartia de don Juan, causa de su hundimiento en los infiernos. Burlarse de un difunto, del hombre que él mismo dio muerte parece una burla cualitativamente distinta de las cometidas contra los vivos, con independencia de su rango, edad o sexo. En este caso existen las condiciones suficientes como para despertar la intervención divina e introducir el plano sobrenatural junto al lado ordinario de la realidad para hacer ver que ambos constituyen una dimensión dual de la existencia en la cosmovisión cristiana. Esta burla, que presenta el carácter de un desafío, se concreta en una invitación a cenar, 
que después se transforma en otra invitación, la del convidado, de ahí, la famosa "doble invitación". Con las palabras de la primera invitación, la de Don Juan, se desencadenan fuerzas sobrenaturales, simbolizadas en el convidado de piedra, enviado de Dios, que acabará con las andanzas del burlador y resolverá la cuestión que nunca se tomó en serio, la de que el tiempo, nuevamente, no es tan largo como él pensaba. El momento de la redención, que don Juan aplaza, en un excitante juego con la vida, le llega de repente $y$, sin apenas tiempo para maniobrar, se le niega. De la misma forma que aplica sus burlas, sin dejar tiempo alguno para la reacción, morirá condenado.

\section{El personaje dual y el problema de resucitar cadáveres}

Es infrecuente en las comedias del Siglo de Oro un personaje activo cuyo desarrollo y crecimiento dramático no se asocie a la materialización de un obstáculo, bien en la forma encarnada de un antagonista fuerte o bien en la existencia de una norma, ley o principio moral que lo obliga a actuar en la dirección contraria a su voluntad. Esa constituye una regla dramática muy eficaz para la generación del deseado conflicto o problema dramático. El Burlador de Sevilla presenta esta rara construcción dramática de un personaje activo sin obstáculo, sin nadie a la altura de su arrollador empuje, sin nada en su horizonte moral capaz de disuadirlo de sus actos. Esta anomalía estructural se resuelve en la última parte de la comedia, cuando el dispositivo enunciativo ve necesario para el significado de la obra dar vida a un personaje que proviene de ultratumba. Se prepara la operación arriesgada de resucitar un muerto con la fuerza suficiente como la que no es "de este mundo", para convertirse en antagonista de don Juan y dotar a la comedia del héroe auténtico del que carecía, pues hasta el momento su protagonista solo muestra una dudosa virtud. Pero la resurrección de cadáveres crea un problema para la forma artística, sobre todo en obras donde el realismo y la medida de lo posible en la naturaleza actúan como coordenadas internas de verosimilitud de la fábula y sus eventos, de manera que si estas leyes de la naturaleza van a quebrantarse deberá justificarse con suficiencia esta necesidad. Puede advertirse que El burlador de Sevilla en sus dos primeras jornadas transcurre por una senda en la que no hay indicios de 
fenómenos sobrenaturales, como en las comedias de santos donde la aparición del demonio, por ejemplo, es probable y hasta esperada. Puede pensarse que El burlador hasta ese momento es una comedia híbrida que adoba elementos de diversos subgéneros, como comedias de capa y espada, de villanos y palatinas, pero a partir de la tercera jornada y con el motivo del comendador de piedra, la comedia introduce su capa más problemática y efectúa su pirueta formal más osada, que conecta la obra con el drama teologal. Con estas especulaciones, que parece razonable plantearlas para llamar la atención sobre la singularidad y originalidad de este drama de ideas, pretendo sugerir la también razonable sorpresa, que un lector informado pudiera albergar en la jornada tercera, cuya expectativa sobre normas del género haría difícil anticipar la resucitación del cadáver del Comendador. Tal evento constituye una ruptura con el modo mimético empleado por la ficción hasta el acto tercero. Northrop Frye (1991), en su teoría de los modos ficcionales, clasificó las ficciones en función del poder de acción del héroe, en relación con los otros personajes y con el medio ambiente. El burlador, hasta el tercer acto, transcurre por el modo mimético elevado, donde puede haber un personaje "superior en grado a los demás hombres pero no al medio ambiente" (1991:54). A partir del encuentro con el Comendador, el modo ficcional del mimético elevado se fusiona con el modo ficcional que incumbe al mito, esto es, cuando hay un personaje que "es superior en clase, tanto a los demás hombres como al medio ambiente, el héroes es un ser divino y la historia un relato acerca de un dios" (1991:53). La voluntad de transmisión de una idea se sobrepone a las exigencias convencionales y a las prácticas llegando a forzar principios y usos para ocasionar una obra distinta. Aquí es donde el autor parece comprender que para resucitar un muerto precisa justificarlo en dos planos: en el nivel de la fábula, esto es, la estricta acción dramática y su lógica operante; y en el nivel global del significado. En el nivel de la fábula, se prepara en dos momentos de gran intensidad y belleza dramática: el falso juramento de don Juan a Aminta (VV. 20115-2121) y la burla macabra y el posterior desafío al difunto Comendador (VV. 2303-2308). En el primer momento, don Juan, a punto de vencer la resistencia de Aminta, se topa con una última traba, la solicitud de un juramento ante dios para que cumpla su palabra 
de matrimonio: "Jura a Dios que te maldiga / si no la cumples". A lo que don Juan replica con la agilidad propia de su genio: "Si acaso / la palabra y la fe mía / te faltare, ruego a Dios / que a traición y a alevosía / me dé muerte un hombre" y en un aparte inmediato matiza: "Muerto / que vivo Dios no permita". El comentario de este falso juramento complementa un aspecto del personaje, pues este demuestra plena conciencia de que algunas acciones verbales no han de tomarse a la ligera, especialmente las que poseen un carácter ceremonial e invocan el nombre de Dios en un juramento. Jurar ante Dios es asunto serio, por eso, como no cumplirá la palabra dada a Aminta, anexa una coda cínica, con la expectativa de que al neutralizar el juramento bloqueará el castigo derivado de su incumplimiento. El raciocinio es ingenuo pero eficaz dramáticamente. La propia fórmula ritual ha de contener su cancelación, es decir, ha de consistir en un acto viciado, que al incumplir la condición de sinceridad exigida para que el juramento sea afortunado, lo transforma en un acto de nulos efectos. John Austin denominó ese hecho discursivo como "un proceso que se auto-anula" (Conferencia IV, 1998:95). Si le han de matar que el ejecutor sea un difunto, lo que se supone lógicamente imposible en el mundo de las leyes y límites humanos en el que se mueve la conciencia profana de don Juan. Don Juan con esta artimaña retórica piensa desactivar el juramento exigido por Tisbea, pero lo que en verdad ocurre es que subestima el poder de dios al creer que su castigo puede verse condicionado por las leyes ordinarias de la naturaleza o cancelarse con la infantil trampa de un juego de palabras, que un filósofo del lenguaje explicaría con suma elegancia más de tres siglos después. La ingenuidad estriba en que don Juan cree que la realidad y las palabras son intercambiables e interdependientes. Pero lo que el autor demuestra aquí y con este evento es el orden ontológico de la realidad representada, dado a través de su valor de verdad poética. Si don Juan no creyera en la seriedad de los juramentos efectuados ante la presencia de Dios, convocados por las propias palabras de la fórmula ritual, si hubiese perdido completamente la fe en la religión católica y no existiesen ya residuos en su sistema de creencias, no tendría sentido pronunciar la coda cínica incluida en el aparte. La aparición de la coda en ese maravilloso golpe de efecto contiene el reflejo de una ambigua superstición, un temor, por tanto, y la 
4 Arellano (1994) recordaba el punto de partida de los trabajos de F. Ruiz Ramón, "Don Juan y la sociedad de El burlador de Sevilla", en Estudios de teatro español clásico y contemporáneo, cit., 71-96; J. E. Varey, "Social criticism in El burlador de Sevilla", Theatre Research International, 2, 1977, 197-221; B. Wardropper, "El tema central de Burlador de Sevilla", Segismundo, 17-18, 1973,9-16. conciencia de un límite con el que, sin embargo, su falta de prudencia se permite jugar colocando en riesgo la vida eterna. El plano de la percepción del temor de Dios, construido de esta forma y expresado en el punto de vista del personaje, rebota al dispositivo formal del género preparando el suceso sobrenatural del muerto resucitado, pues este es, precisamente, el efecto de las palabras de don Juan en el juramento incumplido ante Dios. La lógica de causa y efecto de una superstición o de una creencia acaba de poner en conexión dos planos y en él se mezclarán personajes con distinto poder de acción, dando lugar por tanto también a una fusión de modos. La ficción es autónoma para proveer sus propios mecanismos de coherencia y este pasaje es una muestra de ello. El convidado de piedra es un enviado de Dios, altera el modo ficcional en que transcurre la obra y permite dotar a la obra de un significado que sin esa alteración sería imposible. Como si este evento no fuese suficiente, Tirso motiva un siguiente suceso posterior: el encuentro de don Juan ante el sepulcro del Comendador y la lectura burlona del epitafio. La irresistible tentación de replicar las palabras labradas en mármol le lleva a proferir la sarcástica invitación a un muerto. Con ello, estas dos situaciones convergen preparando la existencia dual de un personaje bisagra, el comendador don Gonzalo y el convidado de piedra, a través del cual el lado profano y el sagrado de la existencia coexisten compartiendo y definiendo las propiedades semánticas del mundo en El burlador de Sevilla.

\section{La crítica social y la admonición individual}

El de la crítica social es un tema de El burlador reiteradamente tratado por críticos y editores ${ }^{4}$. Las famosas palabras de Aminta: "La desvergüenza en España / se ha hecho caballería" (VV. 1962-1963), reflejan un sentimiento que se proyecta hacia fuera de la comedia denunciando a todo un estamento social. Márquez Villanueva apuntaba en su estudio: "el frenesí transgresor de don Juan es inseparable del injusto privilegio social que lo hace posible" (1996:153). Y más adelante: "El donjuanismo requiere a su lado la presencia activa del poder y Tirso lo pone claramente a las puertas de otro discurso de época, como es el del abandono de sus deberes por la nobleza. La corte, más menospreciada que 
nunca, que no es más que un foco de estupidez y de bajas componendas" (1996:153). Las admoniciones se encuentran principalmente en boca de Catalinón y constituyen avisos al pecador, proferidos por su obediente subordinado para corregir su conducta y proceder en consecuencia orientándose ante Dios para la salvación del alma. Quien busque en la obra de Tirso el cliché del irresistible seductor que despierta en la mujer el fuego concupiscente de la pasión amorosa, tal vez se decepcione, pues no existe tal elemento colocado de esa forma. Si persistimos en la busca quizá aparezca como resultado de una lectura sesgada o en una pequeña dosis que no resistiría al fin una interpretación en consonancia con los problemas dramatizados por la comedia. La idea del seductor, de varoniles encantos, se debe a una derivación del mito en recreaciones teatrales y literarias posteriores, probablemente ya bajo el influjo de una estética romántica y, andando el tiempo, a una idea que, ya lejos de la ficción circulará formando parte del manual diagnóstico del psiquiatra, como síndrome de don Juan o, simplemente, donjuanismo.

No es el propósito de este drama sino un rasgo incidental para abordar asuntos como: 1) el del mal gobierno de la república, con la crítica a los privados del rey; 2) la corrupción general de las costumbres y, en especial, la de la joven nobleza; 3) los abusos de los poderosos y la impunidad de sus actos; y 4) el de la salvación del alma en relación con el comportamiento del falso cristiano o cristiano cínico que negocia calculadora y egoístamente el momento para proferir un arrepentimiento que, a todas luces, no es sincero. Especulando un poco más, resulta muy sugestiva la tesis de Bruce $W$. Wardropper para interpretar las comedias de capa y espada de Calderón en comparación con sus dramas de honor, como la doble cara de una misma moneda, cuya solución de continuidad depende de a) si el matrimonio está instaurado en la trama, lo que daría como resultado preocupaciones de honor y celos de casados, o b) si el matrimonio no lo está, dando lugar a las comedias de capa y espada tematizando los destinos de los solteros con sus problemas y celos de amor (Wardropper, 1986:697). Lo que Wardropper sugiere sobre las comedias de capa y espada de Calderón es que habría una crítica implícita del autor al trazar un dibujo frívolo de los tipos galanes y damas, cuyo estilo de vida 
urbana estaría minando desde dentro la conciencia religiosa al mecanizar los actos cotidianos referidos al rito católico:

Según exige la intriga, van a misa, juran por Dios o por un santo, se refieren a su alma inmortal; pero al hacer todo esto siempre ignoran el pleno sentido de estos actos. Tales actos de origen religioso se hacen de una manera automática o habitual. El que toma su religión a la ligera es l'homme moyen sensuel, tan adicto a las actividades cotidianas que difícilmente puede librarse de ellas. Presta tanta atención a lo cultural y lo natural, que apenas concibe la existencia de lo sobrenatural, sin mencionar sus deberes hacia ello. En la cristiandad, en todas las épocas, esta gente forma la inmensa mayoría de los cristianos, contentos de observar las formas religiosas sin llevar una vida de máxima espiritualidad. Tales cristianos despreocupados disminuyen el valor de la religión que profesan: la señal de la cruz viene a ser un ademán ocioso; la asistencia a la iglesia, una obligación social; y el templo mismo, un sitio de reunión. Es mi tesis que la reducción de lo trascendente a la rutina diaria es lo que suministra a Calderón la base de sus comedias de capa y espada. (1986:698).

Resulta muy tentador interpretar a don Juan desde esta perspectiva como una figura que ha evolucionado o caído por la pendiente degradada que conduce a la "reducción de lo transcendente" y a la fatal emergencia de las tentaciones mundanas de lo material y del triunfo definitivo de la carne sobre el espíritu.

En El burlador encontramos la creación de un personaje que atesora un arsenal de principios negativos, desde la óptica de un buen cristiano, rasgos que lo convierten en un modelo invertido y en adalid de la conducta desviada. Su modo de vida desencadena elementos perturbadores de crisis $y$, de imponerse, acarrearía el colapso del sistema social, pues no puede olvidarse que don Juan representa el caso más extremo de la corrupción de la joven nobleza española, cuyos actos no consiguen castigarse por ningún poder terreno. La eficacia de la justicia del rey se ridiculiza como un poder inoperante cuando se trata de imponer castigos a ciertas personalidades, como la suya.

Para completar el cuadro puede resultar complementario una nota histórica sobre las costumbres de la vida sevillana en la época en que se escribe El burlador, "cuando el oro fluía a raudales y la vida bullía tumultuosa en todos los aspectos, 
buenos y malos, en sus plazas y callejas, en sus palacios suntuosos y en los antros del vicio" (Domínguez Ortiz, 1969). De los muchos testimonios que se pueden recoger escogí dos observaciones del padre confesor Pedro de León extractadas por el historiador Antonio Domínguez Ortiz. La primera advierte que "la vida disoluta", característica de la forma de vida representada por la literatura picaresca, ejerce atracción no sólo sobre personas de baja condición, que por falta de opciones se allegaban a esa vida, sino también, y aquí se encienden todas las alarmas, sobre personas de la nobleza española, especialmente los jóvenes:

\begin{abstract}
"Algunas veces se van a ella algunos mozos hijos de gente principal, y de allí los han sacado algunas veces, pero no aprovecha, porque luego se vuelven. Dos años de los que yo fui allá vi a un hijo de un conde de España; y tantas lo sacaba de allí como luego se volvía [...]". Entonces acudió el mozo al Padre León diciéndole que él no quería ser caballero sino jabeguero, y que su padre ya no enviaba por él. (Domínguez Ortiz, 1969, p.32)
\end{abstract}

El hijo de un conde de España del que habla el padre León bien podría recordar a lo que don Juan representa en $E l$ burlador. La otra nota consiste en un valioso testimonio sobre las personas que confiesa el padre para librarlas del pecado y promover la salvación de sus almas:

\begin{abstract}
"Son más fáciles las confesiones de los pícaros y gente baja que no las de los nobles ricos y bien aderezados; [...] Los hombre nobles no dejan cosa enhiesta. De ordinario andan inquietando a las casadas y desasosegando a las doncellas y infamándolas, son jugadores y pendencieros y nunca se confiesan de ordinario, sino de tarde en tarde, y muchas veces por cumplir solamente con la parroquia, y si los hombrecillos bajos tienen algunos vicios, no son de esta naturaleza." (Domínguez Ortiz, 1969, pp. 32-33)
\end{abstract}

Como excelente representante de la comedia española de la época, El burlador de Sevilla evoca los ideales de armonía y equilibrio quebrantados por la acción de su personaje más activo, don Juan. Y los evoca precisamente haciendo notar su ausencia y su estado de perturbación. Conocida es la teoría del drama barroco español concebido a partir de un esquema estructural muy básico en el cual el orden de esa sociedad representada se basa en los sólidos pilares en los que se asienta: la religión católica y la monarquía. Las normas y 
principios emanados de estas dos instituciones, que ocupan los espacios posibles de ese mundo imaginado gracias a la capacidad modeladora de la dramaturgia, no se hallan diseminados equitativamente en todas las almas, sino que se concentran idealizados en las virtudes de un grupo social: la nobleza. Este modo de representar los valores del grupo social de referencia encarnados en la persona-personaje se articula en torno al eje de unos pocos conceptos, como honra, discreción, decoro estamental, gloria y valor, para mostrarnos la virtud cívica y espiritual del caballero y de la dama. Estas no son exclusivamente nociones abstractas sino principios pragmáticos integrados en un programa educativo, como el de la buena crianza, que se obtiene, no tanto por la vía docta del estudio en la universidad, cuanto por la inoculación directa de la transmisión hereditaria. A la sangre, otro subterfugio metafísico, se fía la conducta, por eso cobra importancia la expresión "porque soy quien soy" y los múltiples derivados de este enunciado en la comedia barroca. La "limpieza de sangre", como principio organizador de la república, genera sus propios estatutos resultando un valor permanente evocado o presupuesto en argumentos y tramas. Las variaciones de este asunto en personajes de condición inferior, como el labrador rico o la aldeana honesta, que también pueden adquirir honra, y presumir de discreción, valor y decoro, mostrando determinación ante señores que extralimitan sus funciones, tema recogido en las comedias de Comendadores, obedece a la necesidad de ampliar ese privilegio a grupos sociales que el poder necesita de su lado y no solamente por una cuestión de atractivo folclórico:

No se trata de idealizar la vida del campo con inspiración utópica más o menos lejana o con pretensiones evasivas. Mucho menos de servir a un movimiento libertador campesino. [...] A nuestro parecer lo que se busca es incorporar al campesino a la defensa del orden social vigente, haciendo comprender a todos, $\mathrm{y}$, por tanto, también a él mismo, el interés general que en ello existe y la fuerza de contención del sistema que el campesino puede aportar. (Maravall, 1972:66).

De la misma manera que existe una variación para extender esta virtud a los grupos medios de la sociedad, como secretarios, funcionarios públicos, gremios de oficios, 
artesanos, etc. Pero, a pesar de este intento de extender este derecho, será el caballero, el personaje-tipo estrella destinado a encarnar y difundir esos valores y el ideal del sujeto social. Y cuanto más noble su ascendencia, se presumirá mayor su capacidad para atesorar virtud y honor, y mayor el escándalo si no los portare. Por tanto, este personaje, en el sistema poéticopolítico de la comedia del Siglo de Oro, posee una importante responsabilidad en la cadena de transmisión de valores e ideas, donde la rígida división estamental "que cada uno conserve su lugar, su orden, su concierto" (Cellórigo, en Maravall, 1975, p. 278) funciona como armónico modelo y espejo del mundo. Este aspecto, desde el punto de vista de la expresión de una ideología, puede tenerse como de los más sobresalientes de la comedia barroca. A ese propósito se fiará la exaltación y preservación ejemplar de esas virtudes representadas por el caballero y la dama. De manera que cuando la expectativa de la persona social, representada por el personaje noble, y el sentido de sus acciones entran en conflicto con la expectativa de sus deberes, surgirá la representación de una escala de la conducta desviada en contraste con el modelo ideal representado por las figuras ejemplarizantes. Tanto la exaltación del ejemplo de vida del personaje heroico cuanto la variación de desviaciones en personajes moral y espiritualmente degradados, constituyen una estrategia común que opera produciendo contrastes polarizados y cuyo fin no es otro que el de reforzar los ideales de honra, discreción y decoro, bien por la vía de la imitación o bien por la del repudio (que serían obviamente efectos pretendidos en el acto de lectura/espectáculo). A esta última dirección la podemos llamar, por su recurrencia temática, la línea del desviado ethos aristocrático, mediante la cual numerosas comedias muestran un abanico de conductas de personajes cuyas consecuencias para la manutención y estabilidad del orden social representado son catastróficas y, de entre las cuales, el don Juan de El burlador de Sevilla es probablemente de las más eficientes e intensas en su figuración del mal y en mostrar la pertinaz perseverancia en el error. En un artículo reciente (Zamorano, 2015) sugerí que la figura del agresor sexual en el subgénero del llamado "dramas del poder injusto" (Ruiz Ramón, 2000) servía a Lope de Vega para diseminar el ethos de masculinidad nobiliaria en su variante negativa o desviada. Al proponer un modelo inverso de ejemplaridad en 
la fórmula dramática noble envilecido contra villano ennoblecido, la comedia de Lope hacía partícipes de valores centrales de la ética aristocrática, principalmente organizados mediante la dualidad amor-honor, a grupos subalternos, tradicionalmente excluidos, como labradores ricos y campesinos de sangre limpia, para la mimetización y adopción de tales valores. Además, con ello Lope lograba de una sola tacada la carambola de producir el lugar de lo femenino como un sostén clave del orden previsto en la cosmovisión de dicho ethos. Desde este ángulo es plausible entender a don Juan como un agresor sexual evolucionado, enriquecido y vitaminado con portentosas cualidades negativas, más puro en su intensificada personificación de lo demoniaco. Y, a El Burlador de Sevilla, como una variante de "los dramas del poder injusto", cuyos personajes nobles expresan una deriva preocupante de su ética y de su compromiso, a partir de lo representado por sus "personas", en su sociedad. Pero, como escribía Ruiz Ramón, don Juan es el efecto de una sociedad corrupta, no la causa, (1978). Don Juan es un producto de su sociedad, perfectamente posible para especular con su figura e intentar amonestar a quienes aún no se han condenado para que adviertan que aún hay tiempo para el arrepentimiento sincero. Por ello, El Burlador de Sevilla transciende los dramas de abuso de poder y las comedias del poder injusto, pues en estas, como se sabe, el orden se restaura sin salpicar el verdadero poder, el del rey, y, en El burlador, sin embargo, el rey, en sus funciones dramáticas, se reduce prácticamente a la de un aplicado casamentero. Cuando ha de impartir justicia sobre don Juan, de la familia de los Tenorios, le tiembla el pulso y el castigo resulta risible en proporción a la afrenta cometida, y cuando al final decide condenarlo a muerte, don Juan ya ha sido ejecutado por el enviado de Dios y arrastrado a los infiernos. La justicia terrena ha actuado tarde y mal, siendo inoperante e ineficaz, en consecuencia, no fue justicia, dando lugar a la justicia divina que, esa sí, ajustó las cuentas, niveló las distorsiones, evitando la venganza y restaurando el orden. La polémica sobre el sentido de ese orden restaurado a partir de la solución de matrimonios que el rey propone, se suele saldar con el juicio de que, efectivamente, se trata a todas luces de un final en falso que expresa, estrictamente, un viciado convencionalismo, desprovisto ya de todo o de gran parte de su antiguo significado. 
El autor de El burlador de Sevilla encuentra un modo de describir la incompatibilidad de un personaje con los valores que fundamentan el orden social, atribuyéndole una conducta desviada cuya reiteración e intensificación cruza, como un meteoro, de lo profano a lo sagrado, ofendiendo por igual las leyes humanas y divinas. Si no fuera quien es y representara lo que representa, si su juventud y persona no se asociase al significado político e influencia en la corte de su poderosa familia, los efectos y el daño para la idea del buen gobierno de la republica disminuirían ostensiblemente y, probablemente, también su ofensa a Dios no estaría tan magnificada. No cabe imaginar un personaje como don Juan de extracción hidalga, su autor conseguiría como mucho el trazado de un pícaro y, al menor descuido, un delincuente o un criminal, personajes entremesiles. Con estos mimbres no se podría concebir un personaje con potencial para poner en solfa la corrupción de la élite política y los devaneos de un gobierno banana, empezando por el rey y continuando con su privado y nobles. Y esta es una dimensión de la comedia que, no hace falta extenderse en los motivos ni en sus concomitancias, resulta hoy en día de una vibrante actualidad.

\section{BIBLIOGRAFÍA CITADA}

ARELLANO, I. La máquina del poder en el teatro de Tirso de Molina. Crítica Hispánica. Teatro y Poder. Duquesne University. Vol. XVI, 1994, p. 59-84 http:// dadun.unav.edu/bitstream/10171/34472/1/1994_Arellano_ LaMaquinaDelPoderEnElTeatroDeTirso.pdf

AUSTIN, J. L. Cómo hacer cosas con palabras. Barcelona: Paidós, 1998.

BILHER, H. Más detalles sobre ironía, simetría y simbolismo en El Burlador de Sevilla. Actas del Primer Congreso Internacional de Hispanistas, Oxford, Ed. Pierce \& F. Jones, C. The Dolphin Book, 1968, p. 213-218.

CALDERÓN de la BARCA, P. La vida es sueño. Ed. Ciriaco Morón. Madri: Cátedra, 2001.

CAMPBELL, J. El héroe de las mil caras. México: Fondo de Cultura Económica, 2013. 
CASALDUERO, J. El desenlace de El burlador de Sevilla. Estudios sobre teatro español. Madri: Gredos, 1967, p. 126-142.

DOLFI, L. (2000): El burlador burlado. Don Juan en el teatro de Tirso de Molina. Varia lección de Tirso de Molina (Actas del VIII Seminario del Centro para la Edición de Clásicos Españoles). MadriPamplona, Instituto de Estudios Tirsianos, 2000, p. 31-64. http:// www.cervantesvirtual.com/obra/el-burlador-burlado-donjuan-en-el-teatro-de-tirso-de-molina-0/

DOMÍNGUEZ ORTIZ, D. Crisis y decadencia de la España de los Austrias. Barcelona: Ariel, 1969.

FLURSCHÜTZ, A. El personaje del Don Juan y su desenvolvimiento desde Tirso de Molina 1630 a José Zorrilla 1844. Espéculo. Revista de estudios literarios. Universidad Complutense de Madri, 2010.

https://pendientedemigracion.ucm.es/info/especulo/ numero45/donjuan.html

FRYE, N. Anatomía de la crítica. Caracas: Monte Ávila, 1991.

GARCÍA GUAL, C. La mitología. Barcelona: Montesinos, 1989.

MARAVALL, J. A. Teatro y Literatura en la sociedad barroca. Madri, 1972.

La cultura del barroco. Madri: Ariel, 1975.

MÁRQUEZ VILLANUEVA, F. Orígenes y elaboración de "El burlador de Sevilla". Universidad de Salamanca, 1996.

RUANO de la HAZA, J. M. La relación textual entre El burlador de Sevilla y Tan largo me lo fiáis. Actas del coloquio internacional: Tirso de Molina, del siglo de oro al siglo XX. Ed. Carmen Pinillos, Ignacio Arellano, Blanca Oteiza, Miguel Zugasti. Pamplona, Universidad de Navarra, p. 283-296.

RUBIERA, J. La construcción del espacio en la comedia española del Siglo de Oro. Madri: Arco Libros, 2005.

RUIZ RAMÓN, F. Don Juan y la sociedad del Burlador de Sevilla. Estudios de teatro español clásico y contemporáneo. Madri: Fundación Juan March/Cátedra, 1978, p. 71-96.

Historia del teatro español (desde sus orígenes hasta 1900). Madri: Cátedra, 2000. 
TIRSO de MOLINA, El burlador de Sevilla. Ed. Américo Castro, 1932.

Ed. Alfredo Rodríguez López-Vázquez. Madri: Cátedra, 1996.

Cigarrales de Toledo. Ed. Luis Vázquez Fernández. Madri: Castalia, 1996.

VITSE, M. Don Juan o temor o temeridad. Cahiers du monde hispanique et luso-brésilien, Vol. 13, 1969, p. 63-82. http://www. persee.fr/doc/carav_0008-0152_1969_num_13_1_1734

WARDROPPER, B. El pacto diabólico callado en No hay cosa como callar, de Calderón. Actas del VIII Congreso de la Asociación Internacional de Hispanistas, Madri, Istmo, 1986, p. 697-706.

WATT, I. Mitos del individualismo contemporáneo. Madri: Cambridge University Press, 1999.

ZAMORANO, M. A. Condicionamientos de la enunciación en el teatro aurisecular. Revista Teatro de Palabras (Teapal), Université du Québec à Trois-Rivières, 2014, p. 9-42. http://www.uqtr.ca/ teatro/teapal/TeaPalNum08Rep/MAZamorano.pdf

El agresor sexual y el desviado ethos aristocrático en Peribáñez y Fuenteovejuna, eHumanista (Journal of Iberian Studies), University of California Santa Bárbara, vol. 32, 2015, p. 436-455.

http://www.ehumanista.ucsb.edu/sites/secure.lsit.ucsb.edu. span.d7_eh/files/sitefiles/ehumanista/volume32/4\%20ehum32. zamorano.pdf 


\section{Resumo}

\section{O burlador de Sevilha, don Juan antes do mito}

É plausível supor que muitos leitores possuam uma ideia do dom-juanismo derivada de outras versões e orquestrada na sensibilidade de outras preocupações e épocas. Assombra constatar que aquilo que atraiu posteriormente o interesse de escritores e públicos de diferentes tradições literárias não coincida com o que seu primeiro autor quis tratar, isto é, que a erotomania compulsiva de um personagem que expressa paradoxalmente a inconstância e a impossibilidade de amar, assunto tão atrativo para a mentalidade contemporânea, não foi na peça original nem o tema vertebral nem um fim em si mesmo, senão um meio para teatralizar outras preocupações como a impunidade do poderoso, o bom governo da república, a corrupção da juventude nobiliária e a salvação das almas. Neste artigo comentarei alguns aspectos deste clássico da dramaturgia, com o fim de despertar no leitor não especializado o interesse por seus temas conexos e o complexo intertexto, tanto sincrônico quanto diacrônico, em que inevitavelmente se insere sua interpretação: o teatro espanhol do Século de Ouro e o contexto sociopolítico da época.

Palavras-chave: Don Juan; O burlador de Sevilha; Tirso de Molina; Teatro do Século de Ouro. 


\section{Abstract \\ The Trickster of Seville, Don Juan before the myth}

It's reasonable to assume that many readers have an idea of a "Donjuanism" derived from other versions and orchestrated by other concerns and eras' sensitivity. It is amazing to notice that what attracted the interest of writers and audiences from different literary traditions doesn't match what its first author wanted to address, that is, the compulsive erotomania of a character that paradoxically expresses the inconstancy and the impossibility of love, such an attractive subject to the contemporary mentality, which wasn't the main subject nor an end in itself but a way to dramatize other concerns such as the impunity of the powerful, Republic's good government, the corruption of the nobiliary youth and the salvation of souls. In this article I'm going to discuss some aspects of this classic playwriting in order to awaken the lay reader's interest in its connected themes and the complex intertext, both diachronic and synchronic where inevitably is inserted its interpretation: the Spanish theater of the Golden Age and the sociopolitical context of the time.

Keywords: Don Juan; The trickster of Seville; Tirso de Molina; Golden Age Spanish Theatre. 